\title{
AS FORMULAÇÕES INIBIDORAS DE CORROSÃO E O MEIO AMBIENTE
}

\author{
Fernando Benedicto Mainier ${ }^{1}$ \\ Rosenir Rita de Cassia Moreira da Silva ${ }^{2}$
}

Resumo: O desenvolvimento dos processos químicos tem gerado, progressivamente, o lançamento anual de milhares de formulações químicas no mercado mundial, que incluem desde novos detergentes a inibidores de corrosão. Muitos destes produtos têm sido rotineiramente usados em larga escala e a maioria deles, segundo a Organização Mundial de Saúde, jamais foi estudada com vistas ao comprometimento com a qualidade de vida do homem. Atualmente, o passivo tecnológico não está somente atrelado à obsolescência técnica das máquinas, mas também a outros fatores como instrumentação, controle, conhecimento tecnológico, adequações de "software" e principalmente à tecnologia de produtos químicos utilizados nos diversos segmentos. Já o passivo ambiental corresponde ao investimento que uma empresa deve fazer para corrigir os impactos ambientais gerados e não controlados ao longo dos anos de operação. Antigamente, era apenas um detalhe nas negociações de fusões ou de incorporações empresariais. Hoje, o problema é sério pois, dependendo do valor e do tipo de passivo ambiental, a incorporação poderá não ocorrer, caso o valor da descontaminação ambiental seja tão alta que inviabilize o processo de incorporação. Objetiva-se neste trabalho propor que o uso de inibidores de corrosão esteja associado ao desenvolvimento de tecnologias limpas que contemplem uma avaliação crítica dos produtos químicos usados e das técnicas de proteção ambiental.

Palavras-chave:corrosão, inibidores de corrosão, meio ambiente, tecnologia limpa.

Abstract: The development of the chemical processes has been generating, progressively, the annual release of thousands of chemical formulations in the world market that include from new detergents to the corrosion inhibitors. Many of these products have been used with routine in wide scale and most of them, according to the World Health Organization; it was never studied with views to the compromise with the quality of the man's life. Now, the technological passive it means not only the technical obsolescence of the machines, but also relative to the instrumentation, controls, technological knowledge, software adaptations and mainly the technology of chemical products used in the several segments. Already the passive environmental it corresponds to the investment that a company should do to correct the generated environmental impacts and not controlled along the years of operation. Formerly, it was just a detail in the negotiations of coalitions or of managerial incorporations. Today, the problem is serious because, depending on the value and of the type of passive environmental the incorporation cannot happen, therefore the value of an environmental decontamination can be so high making unfeasible the incorporation process. It is objectified in this work, to propose that the use of corrosion inhibitors is associated to the development of clean technologies that contemplate a critical evaluation of the used chemical products and of the techniques of environmental protection.

Key words: corrosion, corrosion inhibitors, environment, clean technology.

\footnotetext{
${ }^{1}$ Departamento de Engenharia Química, Universidade Federal Fluminense, mainier@vm.uff.br

${ }^{2}$ Departamento de Engenharia Química, Universidade Federal Fluminense, rosenir@vm.uff.br
} 


\section{1 - INTRODUÇÃO}

Os inibidores de corrosão são substâncias que adicionadas ao meio corrosivo objetivam evitar, prevenir ou impedir o desenvolvimento das reações de corrosão, sejam nas fases gasosas, aquosas ou oleosas. A eficiência de proteção oferecida pelos inibidores depende dos metais e ligas bem como da severidade do meio.

Os mecanismos de atuação dos inibidores de corrosão estão baseados na formação de uma barreira ou filme na superfície do material, que impede ou retarda as reações de corrosão, e na alteração do meio corrosivo, tornando-o menos agressivo. Podem ser classificados em: anódicos, catódicos, formadores de filme orgânico, neutralizantes, fase vapor, seqüestrantes de oxigênio dissolvido, etc.

Os inibidores de corrosão são utilizados nos mais diversos segmentos industriais. $\mathrm{Na}$ indústria petrolífera, por exemplo, apresentam grande eficiência anticorrosiva na proteção interna de oleodutos, gasodutos e caldeiras; na área de refino, na produção propriamente dita de petróleo, na injeção de água, nas acidificações, nas recuperações secundárias e nos fluidos de perfuração (Mainier, 1996).

Também atuam com bastante eficiência nas indústrias metalúrgicas e mecânicas, principalmente, nas áreas de decapagem ácida, na fosfatização, na geração de vapor, nos sistemas de refrigeração, nos óleos de corte e nos protetores temporários aplicados aos produtos acabados.

\section{2- TECNOLOGIA DOS INIBIDORES DE CORROSÃO NA LINHA DO TEMPO}

Existem registros (Nathan, 1973) que documentam, no início do século $\mathrm{XX}$, o uso de misturas de melaços, amidos e óleos vegetais na proteção de peças de aço-carbono após a decapagem ácida.

Na década de 1920, foram utilizadas por Thresh (1921, 1922) e Evans (1927) adições de silicato de sódio na proteção de aço-carbono sujeitas a águas agressivas. É importante assinalar que o silicato é um produto praticamente inócuo e que não causa problemas ambientais.

Segundo Uhlig (1966), na década de 1930, foram utilizadas na decapagem de aço-carbono várias substâncias orgânicas tais como: toluidinas, fenilhidrazina, piridinas dimetilamina, dibutilamina, quinoleinas, etc. Ainda naquela década foi recomendada pela American Society of Refrigeration of Engineers a utilização de cromato de sódio juntamente com hidróxido de sódio visando à proteção de aço-carbono imerso em salmouras de cloreto de sódio ou de cloreto de cálcio (Speller, 1930, 1935). Tanto os produtos orgânicos citados anteriormente quanto o cromato de sódio são substâncias de alto poder tóxico.

Na década de 1940, o cromato de sódio se destaca e se consagra na proteção anticorrosiva dos sistemas de água de refrigeração, principalmente, nas águas com alta salinidade (Darrin, 1946, 1949). Também sais e óxido de arsênio foram usados com excelentes resultados na decapagem de aço-carbono (Hudson et al., 1967). Entretanto, é sabido que desde o século XVIII o arsênio e seus compostos são considerados venenos fortíssimos.

A partir da década de 1950, notase um avanço e um direcionamento da tecnologia dos inibidores de corrosão no desenvolvimento de sínteses orgânicas orientadas na obtenção de produtos orgânicos com grande eficiência na capacidade de adsorção e formação de filmes aderentes à superfície metálica. Porém, a maioria destes produtos mostrou-se extremamente tóxica, já que, na época, não havia uma preocupação nem com saúde humana e nem com o meio ambiente, objetivando apenas a demanda industrial.

O banimento de compostos de arsênio utilizados nos sistemas de acidificação, devido ao seu potencial tóxico, ocorreu a partir da década de 70 . Quanto ao cromato, tem havido uma 
redução (Mainier, 1985) do uso devido ao seu alto potencial tóxico (Felcan, 1988); conseqüentemente novas rotas já indicam o uso de molibdatos (Mainier \& Marques, 1991) e outros produtos. As grandes empresas praticamente têm desativado o uso de cromato nos sistemas de refrigeração, entretanto o mesmo não tem acontecido nas pequenas e médias torres de refrigeração de supermercados, lojas de departamentos e hotéis. Estima-se que $90 \%$ destas instalações, localizadas na região do Rio de Janeiro e de São Paulo, ainda utilizam cromato na ordem de 600 a $1000 \mathrm{ppm}$.

Vê-se claramente nestas rotas tecnológicas apresentadas que, no início do século (décadas 10 e 20), os produtos utilizados como inibidores de corrosão eram inócuos. Entretanto, a necessidade de maior eficiência de proteção anticorrosiva levou à síntese de produtos mais complexos e conseqüentemente mais tóxicos.

Presentemente existe uma preocupação ambiental no sentido de minimizar ou utilizar produtos não tóxicos e compatíveis com o meio ambiente (Darling \& Rakshpal, 1998) evitando impactos e passivos ambientais. Daí a necessidade de criar tecnologias limpas direcionadas aos inibidores de corrosão.

\section{ATECNOLOGIAS LIMPAS APLICADAS AOS INIBIDORES DE CORROSÃO}

É difícil fazer previsões, entretanto, é fundamental o estabelecimento da responsabilidade diante do futuro, principalmente sobre a questão dos contaminantes e da geração de resíduos, embora esteja intrinsecamente ligada à vigilância permanente das agências ambientais, às Organizações Não Governamentais (ONGs), às repercussões ambientais e à saúde pública, tornando obrigatório o conhecimento das rotas industriais e a imposição de padrões e parâmetros críticos

De certa forma tais problemas podem ser resolvidos ou contornados através da avaliação de impacto ENGEVISTA, v. 6, n. 3, p. 106-112, dezembro 2004 ambiental que compreende um estudo realizado para identificar, predizer, interpretar, prevenir as conseqüências ambientais que determinadas ações, planos, projetos, programas e instalações industriais possam causar à saúde, segurança e ao bem-estar dos seres humanos e seu entorno.

Atualmente, a maiorias dos programas de avaliação de impactos ambientais está associada ou interligada aos vários programas de gestão e vigilância ambiental. O Programa de Vigilância Ambiental Global do Programa das Nações Unidas para o Meio Ambiente - PNUMA procura romper um abismo existente de incertezas científicas que levam ao alarmismo inconsciente ou ao descrédito das informações relativas aos sistemas ambientais. Este programa, destituído de objetivos políticos-econômicos, tem como meta apresentar as informações das mudanças ambientais a governos, cientistas, indústrias, enfim, a todos que necessitem informações sobre o tema. É monitorado pelo Sistema de Monitoramento Ambiental Global (GEMS) do qual participam 142 países, pelo Sistema Mundial de Informação Ambiental (INFOTERRA) e pelo Registro Internacional de Substâncias Potencialmente Químicas (IRPTC).

Segundo Maia (1995) a evolução do conceito de meio ambiente tem mudado com relação à década de 1960 quando era tratado como algo a ser defendido, com ênfase na conservação. Até a pouco tempo a política de meio ambiente tinha um aspecto normativo e as informações eram baseadas nos padrões de poluição. Entretanto, a partir de 1986, tornou-se obrigatória apresentação de estudos de impacto ambiental relativos as implantações de programas ou de indústrias objetivando assegurar que os efeitos ambientais, sociais, econômicos e políticos sejam identificados e avaliados na fase de planejamento de projeto, antes que as decisões de implantação sejam adotadas.

Na ótica de Mainier (1993) é necessário o desenvolvimento de uma consciência técnica crítica que deve ser 
construída na sociedade, principalmente na Universidade, visando o entendimento das rotas industriais, as qualificações e a quantificações dos possíveis contaminantes e resíduos gerados durante o processo industrial. E, finalmente, como meta-objetivo, buscar sempre rotas industriais que possam prever o passivo ambiental e convergir para as tecnologias limpas.

O passivo ambiental, segundo Costa (1998), corresponde ao investimento que uma empresa deve fazer para corrigir os impactos ambientais gerados e não controlados ao longo dos anos de operação. Antigamente, era apenas um detalhe nas negociações de fusões ou de incorporações empresariais. O problema agora é sério pois, dependendo do valor e do tipo de passivo ambiental, a incorporação empresarial poderá não ocorrer. $\mathrm{O}$ valor de uma descontaminação ambiental poderá ser tão alta que inviabiliza o processo de incorporação empresarial.

De acordo com Lippi (1998), a Rhodia (S. Paulo) é um dos exemplos desse problema, que até hoje paga pela herança ambiental adquirida na compra da Clorogil, empresa fabricante de produtos conservantes para madeiras. Em 1994, foi condenada pela Justiça a descontaminar quatro áreas em $\mathrm{S}$. Vicente (S. Paulo), anteriormente contaminadas pelos resíduos gerados e dispostos pela Clorogil. Nestas áreas constatou-se o alto índice de produtos relacionados como cancerígenos e capazes de gerar mutações genéticas.

Outro exemplo que merece reflexão, segundo a Gazeta Mercantil (Lippi,1998), é o caso da Indústria Matarazzo, em S. Caetano do Sul (S. Paulo), que produzia o agrotóxico BHC. Ao falir deixou um terreno com um passivo ambiental da ordem de 20 milhões de dólares. Vários grupos internacionais já se interessaram pelo terreno para construção de "shoppings", entretanto desistiram ao saber do valor do passivo ambiental.

Essas contaminações do solo aconteceram em décadas passadas, contudo hoje, convém lembrar, que esse passivo ambiental estaria enquadrado na Lei $n^{\circ}$ 9605/98 como infrações ambientais, podendo responsabilizar criminalmente a empresa e os seus executivos.

É impossível voltar ao passado para re-engenheirar os processos de fabricação e auditorar criteriosamente as tecnologias que geraram tais contaminações. Porém, os fatos relatados anteriormente servem de alerta e balizamento para a formulação de tecnologias que respeitem o meio ambiente.

Tem-se a sensação que a tecnologia desta década está orientada para transformações de sua própria existência, com inovações rápidas e superpostas sobre as próprias inovações que produz. Sob esta nova ordem, os processos, os equipamentos e os materiais ficam entre o impasse do uso imediato e a obsolescência técnica acelerada. Estes fatos, conseqüentemente, levam o sistema empresarial à tomada de decisão, uma vez premido pelo envelhecimento precoce do seu produto torna-se obrigatório o lançamento do novo, rapidamente, no mercado consumidor. Para que esta rapidez industrial aconteça, são queimadas na maioria das vezes, etapas fundamentais que acabam trazendo problemas no futuro.

No caso específico das indústrias químicas nem sempre é possível estabelecer estas transformações imediatas. Os processos geralmente são tradicionais, alicerçados nos conceitos da físico-química, que impedem as mudanças bruscas e sem base, principalmente, quando o mundo está direcionado e centrado no eixo da preservação ambiental.

Nesse sentido, a ótica de Tigre et al. (1994) mostra que a decisão empresarial de investir em tecnologias ambientais é função dos seguintes fatores:

- concorrência entre os pares;

- pressão dos clientes;

- pressão da opinião pública; 
- incentivo e/ou pressão dos governos.

É claro que as pressões forçam tomadas de decisões empresariais, entretanto os próprios empresários começam a perceber que investir na preservação ambiental pode ser uma fonte de receita e não um fardo ou uma obrigação legal.

Os "selos verdes", significando produtos fabricados sem criar impactos ambientais, podem se constituir num novo mercado mas também podem ser considerados como barreiras alfandegárias para vários países. O Canadá e alguns países da Comunidade Européia já condicionam o "selo verde" às importações de certas matérias primas que geram problemas ambientais. A celulose obtida industrialmente por tratamentos à base de substâncias cloradas tem perdido mercado para as celuloses tratadas com peróxido de hidrogênio.

Tem-se notado um aumento significativo nos custos de tratamento, principalmente, em função da redução dos níveis de contaminação impostos pelas Agências Governamentais e coadjuvado pelas intensas campanhas de esclarecimento da opinião pública e das auditorias ambientais realizadas pelas organizações não governamentais (ONGs), no sentido de evitar e minimizar as contaminações ambientais.

Para sanar o grande desperdício e a emissão de efluentes para o meio ambiente, têm sido adotadas nas empresas dois tipos de rotas tecnológicas: o tratamento dos resíduos no final do processo (end-of-pipe) e a tecnologia limpa (clean tecnology).

A primeira engloba a concentração e a disposição controlada de resíduos em áreas específicas, dispersão de efluentes em menor escala e/ou transformações de resíduos aceitáveis pelas Agências Ambientais.

A tecnologia limpa pode ser definida como o conjunto de métodos e de técnicas que objetiva a minimização dos resíduos e tem como eixo central a preservação do meio ambiente. As matérias primas e a energia necessárias ao processo devem ser otimizadas e integradas ao ciclo de produção e consumo de tal forma a minimizar o impacto ambiental. A operação, as condições operacionais e os equipamentos envolvidos devem ser gerenciados com base na gestão crítica que visa diminuir a possibilidade de falhas e danos. Finalmente, a tecnologia limpa deve ter como princípio fundamental o objetivo de propiciar uma melhor qualidade de vida para o homem.

Atualmente existe uma preocupação com as formulações de inibidores de corrosão tendo em vista as normas e os procedimentos adotados pelas agências de controle ambiental e, de certo modo, pela formação da consciência de preservação do meio ambiente na sociedade, principalmente, pelas prováveis contaminações do solo e dos recursos hídricos frente ao desenvolvimento, organizado ou não, do sistema urbano e industrial.

Visando discutir o uso de inibidores de corrosão frente ao presente e ao futuro e considerando que ainda são utilizadas formulações tóxicas, porém eficientes, na proteção anticorrosiva, são propostas medidas a curto e médio prazo, que devem ser amplamente discutidas com base na formação da consciência técnica crítica.

As propostas apresentadas, a seguir, não estão ordenadas visando prioridades ou estabelecimentos de critérios de escolha, entretanto, representam filosofias ou técnicas que podem ser implementadas visando o impacto ambiental causado pelos inibidores de corrosão:

- banimento de formulações inibidoras com alto teor tóxico;

- encapsulamento do inibidor de corrosão;

- inibidores de corrosão sob forma sólida;

- desenvolvimento de formulações biodegradáveis;

- substituição dos solventes tóxicos por solventes não tóxicos 
- tratamentos específicos para eliminação da toxidez dos inibidores de corrosão;

- condicionamento e transporte (uso de containers específicos de responsabilidade do fabricante do produto e que não podem ser descartados no meio ambiente) ;

- descarte ou emissão zero.

A medida mais importante da atualidade consolida-se no estabelecimento de uma política que promova a desativação de formulações inibidoras tóxicas, principalmente, aquelas que afetem, pelo contato ou pela inalação, a saúde do trabalhador ou as que causem sérios danos ambientais.

Por outro lado, a técnica de obter inibidores de corrosão sob a forma sólida ou o encapsulamento do produto mostrase bem promissora, enquanto 0 tratamento ou eliminação de despejos industriais contendo inibidores de corrosão é difícil e o custo é alto.

\section{4 - CONCLUSÕES}

O presente trabalho permite tirar as seguintes conclusões:

- a corrosão é um permanente desafio ao homem, pois quanto mais a ciência cria e evolui e a tecnologia aplica e avança, mais ela encontra espaço e maneiras de se fazer presente;

- é fundamental que as formulações inibidoras estejam centradas no futuro ao ser compatível com os segmentos industriais, com homem e com o meio ambiente;

- é importante que a pesquisa de novos produtos, orgânicos ou inorgânicos, seja orientada para atender aos objetivos industriais, mas sob critérios rígidos e conscientes, de tal forma que, esses produtos não se direcionem na contramão dos desejos e das metas da sociedade;

- é imprescindível que o condicionamento e o transporte das formulações inibidoras estejam sendo realizados, de tal modo, que não venham interferir na saúde do trabalhador;

- é fundamental que as adições de inibidores de corrosão nos processos industriais sejam monitoradas e estejam suportadas na emissão zero de contaminantes para o meio ambiente ou sejam enquadrados nos critérios das tecnologias limpas;

- é importante a formação da consciência técnica crítica fundamentada na responsabilidade técnica e social dos fabricantes das formulações comerciais oferecidas ao sistema industrial.

\section{5- REFERÊNCIAS BIBLIOGRÁFICAS}

COSTA, A.B., Passivo ambiental: uma preocupação adicional, São Paulo, Gazeta Mercantil, 03/09/1998, p.C-1.

DARLING, D., RAKSHPAL, R. Green chemistry applied to corrosion and scale inhibitors, Materials Performance (NACE), vol 37, n 12, December, 1998, p 42-45.

DARRIN, M. Chromate corrosion inhibitors in chloride systems. Ind. Eng. Chem., v 38, n. 4, April, 1946, p.368373.

DARRIN, M. Corrosion inhibition with chromate - Gas processing plants and refineries, Oil \& Gas J., 1949, Feb., p.156-161

EVANS, U.R. Journal Chemical Society and Chemical Industrial 46, 1927, p. $354 \mathrm{~T}$

FELCAN, J., Elementos químicos importantes para a vida: cromo. Rio de Janeiro: Editora Rebizzi, 1988, p.101.

HUDSON, R.M.; LOONEY, Q.L.; WARNING, C.J. Coal tar base fractions as pickling inhibitors in hydrochloric and sulphuric acid solutions. Brit. Corros. J., 2, no.3, 1967, p.81-86

LIPPI, R. Passivo ambiental prejudica fusões e aquisições São Paulo, Gazeta Mercantil, 21/08/1998, p.A-8. 
MAIA, A.A. Meio ambiente, qualidade e gestão ambiental. Revista FEEMA, Ano IV, $\mathrm{n}^{\circ}$ 18, Julho/Agosto, Rio de Janeiro: Secretaria de Estado de Meio Ambiente, 1995, p.34-36.

MAINIER, F. B., Estudo da viabilidade da diminuição da adição de cromatos como inibidores de corrosão em fluidos de completação. Anais: Seminário de Completação e Estimulação de Poços, 8, Salvador, 1985, p.36

MAINIER, F.B., A qualidade do ácido clorídrico produzido em função das rotas tecnológicas usuais e sua influência direta ou indireta nos produtos finais. Tese de concurso público para Professor Titular da Universidade Federal Fluminense, Escola de Engenharia, Universidade Federal Fluminense 1993, 187p.

MAINIER, F.B. Inibidores de corrosão na indústria de petróleo: ontem, hoje e amanhã, Anais: $5^{\circ}$ Congresso LatinoAmericano de Hidrocarbonetos CONEXPO-ARPEL-96, 13 a 17 outubro, Rio de Janeiro, 1996, 8p.

MAINIER, F.B., MARQUES, L.C.C., Inibidor de corrosão à base de molibdato para fluidos salinos, Petro \& Química, ano XV, n 144, outubro, 1991, p. 36-39

NATHAN, C.C. Corrosion Inhibitors, Houston, Texas: National Association of Corrosion Engineers (NACE), 1973.

SPELLER, F.N. Corrosion in refrigeration plant, American Society of Refrigeration of Engineers, Circ. 10, 1930.

Corrosion, causes and

prevention. New York: McGraw-Hill Book Co, 1935, p.617-618.

THERESH, J.C., Analyst, $\mathrm{n}^{\circ}$ 46, 1921, p.270;

Analyst, $n^{\circ}$ 47, 1922,

p.459

TIGRE, P. B.; WANDERLEY, A.; FERRAZ, J.C.; RUSH, H. Tecnologia e meio ambiente. oportunidades para indústria. Rio de Janeiro: Instituto de Economia Industrial, UFRJ, 1994, 139p.

UHLIG, H.H. The corrosion handbook, New York: John Wiley \& Sons, Inc, 1966, p.909-912 